\title{
MicroRNA-196a promotes cervical cancer proliferation through the regulation of FOXO1 and p27 $7^{\text {Kip1 }}$
}

\author{
$\mathrm{T} \mathrm{Hou}^{1,3}, \mathrm{~J} \mathrm{Ou}^{2,3}, \mathrm{X} \mathrm{Zhao}^{1}, \mathrm{X} \mathrm{Huang}^{1}, \mathrm{Y} \mathrm{Huang}^{1}$ and $\mathrm{Y}$ Zhang ${ }^{*, 1}$ \\ ${ }^{1}$ State Key Laboratory of Oncology in South China, Sun Yat-sen University Cancer Center, Collaborative Innovation Center for \\ Cancer Medicine, Guangzhou, GD 510060, China and ${ }^{2}$ Department of Obstetrics and Gynecology, The First Affiliated Hospital of \\ Sun Yat-Sen University, Guangzhou, GD 510080, China
}

Background: The phosphoinositide 3-kinase (PI3K)/Akt signalling pathway appears to be a key regulator in cervical carcinogenesis. However, the downstream regulatory mechanism of PI3K/Akt signalling remains largely unknown.

Methods: The expression of miR-196a in cervical cancer cell lines and cervical cancer tissues was examined using real-time PCR. The effects of miR-196a on PI3K/Akt signalling and cellular proliferation were evaluated by bromodeoxyuridine labelling, 3-(4,5Dimethyl-2-thiazolyl)-2,5-diphenyl-2H-tetrazoliumbromide, colony formation assays and luciferase assays.

Results: The expression level of miR-196a was markedly increased in cervical cancer tissues and cell lines compared with normal cervical tissue and normal cervical squamous cells. Upregulation of miR-196a was correlated with advanced tumour stage and poor overall and recurrence-free survival in cervical cancer patients. Upregulation of miR-196a enhanced G1/S-phase transition and the proliferative ability of cervical cancer cells, whereas suppression of miR-196a had the opposite effect. Using bioinformatics and biological approaches, we showed that FOXO1 and p27 Kip1, two key effectors of PI3K/Akt signalling, were direct targets of miR-196a.

Conclusions: Our findings suggest that miR-196a has an important role in promoting human cervical cancer cell proliferation and may represent a novel therapeutic target of microRNA-mediated suppression of cell proliferation in cervical cancer.

Cervical cancer is one of the most common malignant tumours of the female reproductive tract (Jemal et al, 2011). Approximately 500000 new cases are diagnosed each year, of which an estimated 274000 will prove to be fatal (Haie-Meder et al, 2010). In the last several decades, significant advances have been made in understanding the mechanism of cervical carcinogenesis (Castellsague et al, 2006). However, the detailed mechanism of cervical carcinogenesis remains largely unknown. Therefore, identifying key factors in cervical cancer development may provide potential therapeutic targets for the prevention and treatment of cervical cancer.

The phosphoinositide 3-kinase (PI3K)/Akt signalling pathway appears to be a key regulator in cervical carcinogenesis, as it is activated in more than $90 \%$ of cervical carcinomas (Du and Wang, 2012). Akt signalling is a downstream target of HPV E6/E7 oncoproteins, which have been identified as major mediators of cervical cancer development (Castellsague, 2008). The expression of HPV-type 16 E7 caused upregulation of Akt activity and inhibition of cell hyperproliferation via interaction with the $\mathrm{Rb}$ protein (Menges et al, 2006). Similarly, HPV-type 18 E6 protein upregulates the phospho-PI3K protein, which correlates with activated MAPKs and cell proliferation (Chakrabarti et al, 2004). Gene expression profiling also suggested that the PI3K/Akt pathway represents a therapeutic target in cervical cancer (Schwarz et al, 2012). Therefore, targeting PI3K/Akt signalling pathway might be an attractive strategy for inhibiting tumour growth and invasion of cervical cancer.

MicroRNAs (miRNAs) are small non-coding, single-stranded RNAs that control gene expression by inhibiting mRNA

\footnotetext{
*Correspondence: Dr Y Zhang; E-mail: zhangyannapds@gmail.com
}

${ }^{3}$ These authors contributed equally to this work.

Received 1 August 2013; revised 28 October 2013; accepted 17 December 2013; published online 14 January 2014 
translation or by inducing mRNA degradation (Ambros, 2004; Kloosterman and Plasterk, 2006). MicroRNAs can regulate multiple steps of tumour growth and progression by modulating the expression of many genes. In recent years, the role of miRNAs in regulating the expression of cell cycle-related genes at the posttranscriptional level has been investigated. For example, miR-96 has been shown to promote human breast cancer cell proliferation by downregulating FOXO3a expression (Lin et al, 2010). miR-194 has been suggested to act as a tumour suppressor that inhibits metastasis of non-small cell lung cancer by targeting BMP1 and cyclin-dependent kinase inhibitor p27 $7^{\mathrm{Kip} 1}$ (Wu et al, 2013). However, there have been few detailed studies on the role of miRNAs in cervical cancer.

In the current study, we identified miR-196a, which was selected from a previously published microarray data set (NCBI/GEO/ GSE6188), as a candidate oncogenic miRNA in cervical cancer. Our in vitro studies showed that expression of miR-196a was markedly elevated in cervical cancer cells and surgical cervical cancer specimens, and that miR-196a expression was correlated with tumour stage and clinical prognosis of cervical cancer. Furthermore, we demonstrated that miR-196a promotes cervical cancer cell proliferation by binding to the $3^{\prime}$-untranslated region (UTR) of FOXO1 and p2 $7^{\mathrm{Kip} 1}$ mRNA. Thus, miR-196a may have a fundamental role in the development and progression of cervical cancer.

\section{MATERIALS AND METHODS}

Patients and tissue specimens. This study was conducted on 92 snap-frozen cervical cancer samples, which were histopathologically diagnosed at the Sun Yat-Sen University Cancer Center (SYSUCC) between 2006 and 2008. Clinical and clinicopathological classification and staging were performed according to the International Federation of Gynecology and Obstetrics criteria (Pecorelli, 2009): 53 were allocated to stage IB1, 14 to stage IB2, 15 to stage IIA1, 6 to stage IIA2 and 4 to stage IIB. Follow-up after surgical resection was available for all patients with a median time of 45.6 months (range 1.2-60 months). The overall survival and recurrence-free survival time were calculated as the time from the date of the primary surgery to the date of death or first recurrence. In all 92 snap-frozen cervical cancer samples, the HC2 assay (Digene Corporation, Gaithersburg, MD, USA) was used to detect the presence of high-risk HPV DNA, including DNA from HPVtype $16,18,31,33,35,39,45,51,52,56,58,59$ and 68 . The HPV DNA testing was performed according to the manufacturer's instructions. High-risk HPV was detected in 82 cases, which gave an overall infection rate of $89.1 \%$. In addition, 10 pairs of freshly prepared cervical tumour and matched normal tissue from adjacent regions were collected at SYSUCC in 2011. In order to use these clinical materials for scientific purposes, both patientinformed consent and approval from the Institutional Research Ethics Committee were obtained.

Cell culture. Primary normal cervical squamous cells (NCSC) obtained from adjacent non-cancerous cervical tissue were cultured in keratinocyte serum-free medium (Invitrogen, Carlsbad, CA, USA) supplemented with epithelial growth factor, bovine pituitary extract and antibiotics ( $1 \%$ streptomycin and $1 \%$ penicillin). Cervical cancer cell lines (MS751, C33A, HeLa, HeLa229, SiHa, HCC94, CaSKi, HT-3 and ME-180) were grown in DMEM (Invitrogen). All cells were supplemented with $10 \%$ fetal bovine serum (HyClone, Logan, UT, USA) and 1\% penicillin/streptomycin (Invitrogen).

RNA extraction, reverse transcription and real-time PCR. Total miRNA from cultured cells and fresh surgical cervical cancer tissues was extracted with the mirVana miRNA Isolation Kit
(Ambion, Austin, TX, USA) according to the manufacturer's instructions. Complementary DNA was synthesised from $5 \mathrm{ng}$ of total RNA using the Taqman miRNA reverse transcription kit (Applied Biosystems, Foster City, CA, USA). Expression levels of miR-196a were quantified using the miRNA-specific TaqMan MiRNA Assay Kit (Applied Biosystems). Real-time PCR was performed using the Applied Biosystems 7500 Sequence Detection System. The expression of miR-196a was defined based on the threshold cycle $(\mathrm{Ct})$, and relative expression levels were calculated as $2^{-[(\mathrm{Ct} \text { of miR196a) - (Ct of U6)] }}$ after normalisation with reference to expression of U6 small nuclear RNA. The primers used are shown in Supplementary Table 1. Expression data were normalised to the geometric mean of the housekeeping gene $\alpha$-tubulin to control for the variability in expression levels and calculated as

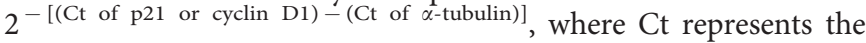
threshold cycle for each transcript.

Western blotting. Western blotting was performed according to standard methods as previously described (Li et al, 2008). Cells were collected in sampling buffer $\left(62.5 \mathrm{mmoll}^{-1}\right.$ Tris- $\mathrm{HCl}(\mathrm{pH}$ 6.8), $10 \%$ glycerol, $2 \%$ SDS) and heated for $5 \mathrm{~min}$ at $100{ }^{\circ} \mathrm{C}$. The protein concentration was determined by the Bradford assay using a commercial kit (Bio-Rad, Hercules, CA, USA). Equal quantities of protein were separated on 10\% SDS-polyacrylamide gels and transferred onto polyvinylidenedifluoride membranes (Roche, Mannheim, Germany). The membranes were probed with polyclonal rabbit antibody against FOXO1 (1:1000; Cell Signaling, Danvers, MA, USA), p27 (1:1000; Cell Signaling), p21 (1:1000; Cell Signaling) and cyclin D1 (1:1000; Cell Signaling). Primary antibody binding was detected using horseradish peroxidaseconjugated anti-rabbit IgG $(1: 3000)$ and enhanced chemiluminescence (Pierce, Rockford, IL, USA) according to the manufacturer's protocols. The membranes were stripped and re-blotted with an anti- $\alpha$-tubulin mouse monoclonal antibody (1:1000; Sigma, St Louis, MO, USA) as a loading control.

Plasmids and transfection. The FOXO1-3'-UTR comprises 3385 base pairs (bp) with a conserved miR-196a-binding site at nucleotides $470-476$. The $\mathrm{p} 27^{\mathrm{Kip} 1} 3^{\prime}$-UTR comprises $1344 \mathrm{bp}$ with a conserved miR-196a-binding site at nucleotides 245-251. Human FOXO1 (without $3^{\prime}$-UTR) and FOXO1-3'-UTR (with $3^{\prime}$-UTR) were amplified by PCR amplification from a human liver cDNA library (Clontech, Mountain View, CA, USA) and cloned into the pMSCV vector. The regions of FOXO1-3'-UTR and p27 $23^{\text {Kip1 }}$ $3^{\prime}$-UTR were generated by PCR from NCSC and cloned into the pGL3 vector (Promega, Madison, WI, USA). The primers used are shown in Supplementary Table 1. The FOXO1 reporter plasmid p3xIRS-MLP-luc was constructed as previously described (Huang et al, 2005). The miR-196a mimics, negative control (NC) and anti-miR-196a inhibitor were purchased from RiboBio Co. Ltd. (Guangzhou, Guangdong, China). MicroRNA or miRNA inhibitor was transfected with Lipofectamine 2000 reagent (Invitrogen) according to the manufacturer's instructions.

Luciferase assays. Cervical cancer cells $\left(3.5 \times 10^{4}\right)$ were seeded in triplicate in 24-well plates and allowed to settle for $24 \mathrm{~h}$. One hundred ng each of the p3x-IRS-MLP-luciferase plasmid, pGL3FOXO1-3'-UTR (wt/mu) plasmid, pGL3-p2 $7^{\text {Kip1 }}-3^{\prime}-$ UTR $(w t / m u)$ plasmid or control luciferase plasmid plus $1 \mathrm{ng}$ of the pRL-TK renilla plasmid (Promega) were then transfected into cervical cancer cells using Lipofectamine 2000 (Invitrogen) according to the manufacturer's recommendations. Luciferase and renilla activity were measured $48 \mathrm{~h}$ after transfection using the Dual Luciferase Reporter Assay Kit (Promega) according to the manufacturer's instructions. Three independent experiments were performed and the data were presented as the mean \pm s.d.

BrdU labelling. Cells grown on coverslips (Fisher, Pittsburgh, PA, USA) at $70 \%$ confluence were incubated with bromodeoxyuridine 
(BrdU) for $1 \mathrm{~h}$. Cells were then stained with anti-BrdU antibody (Upstate, Temecula, CA, USA) according to the manufacturer's instructions. Gray level images were acquired under a laserscanning microscope (Axioskop 2 plus, Carl Zeiss Co. Ltd., Jena, Germany).

Colony formation assays. Cells were plated into $60 \mathrm{~mm}$ dishes $\left(0.5 \times 10^{3}\right.$ cells per plate $)$ and cultured at $37^{\circ} \mathrm{C}$ in $5 \% \mathrm{CO}_{2}$. After 10 days, colonies were stained with $1.0 \%$ crystal violet for $30 \mathrm{~s}$ after fixation with $10 \%$ formaldehyde for $5 \mathrm{~min}$.

MTT assay. Cells were seeded into 96-well plates at indicated time points with $100 \mathrm{ml}$ sterile 3-(4,5-Dimethyl-2-thiazolyl)-2,5-diphenyl$2 \mathrm{H}$-tetrazoliumbromide (MTT) dye $\left(0.5 \mathrm{mg} \mathrm{ml}^{-1}\right.$, Sigma) for $4 \mathrm{~h}$ at $37^{\circ} \mathrm{C}$. The medium was then removed and $150 \mu \mathrm{l}$ dimethyl sulphoxide (Sigma) was added. The absorbance was measured at $570 \mathrm{~nm}$, with $655 \mathrm{~nm}$ as the reference wavelength. All experiments were performed in triplicate.

Flow cytometry analysis. Cells were collected by trypsinisation, washed in ice-cold PBS and fixed in $80 \%$ ice-cold ethanol in PBS. Before staining, the cells were pelleted by centrifugation at $4{ }^{\circ} \mathrm{C}$ and resuspended in chilled PBS. Bovine pancreatic RNase (Sigma) was added at a final concentration of $2 \mathrm{mg} \mathrm{ml}^{-1}$. The cells were then incubated at $37^{\circ} \mathrm{C}$ for $30 \mathrm{~min}$, followed by incubation in $20 \mathrm{mg} \mathrm{ml}^{-1}$ of propidium iodide (Sigma-Aldrich, St Louis, MO, USA) for $20 \mathrm{~min}$ at room temperature. Fifty thousand cells per group were analysed on a flow cytometer (FACSCalibur; BD Biosciences, San Jose, CA, USA).

Statistical analysis. The two-tailed Student's $t$-test was used to evaluate the significance of the difference between two groups in all pertinent experiments. Overall and recurrence-free survival curves were plotted according to the Kaplan-Meier method, with the log-rank test applied for comparison. The correlation between
miR-196a and FOXO1 expression was evaluated using Pearson's test. $P$-values $<0.05$ in all cases were considered statistically significant.

\section{RESULTS}

miR-196a is upregulated in cervical cancer cell lines and cervical cancer tissues. To examine levels of miR-196a expression in cervical cancer, we conducted real-time PCR to measure the miR196a expression in 9 cervical cancer cell lines and in 10 pairs of cervical cancer tissues and their adjacent normal tissues (NCSC). The results showed that miR-196a was markedly increased in all nine cervical cancer cell lines (MS751, C33A, HeLa, HeLa229, SiHa, HCC94, CaSKi, HT-3 and ME-180) compared with NCSC (Figure 1A). Consistent with the results found in the cell lines, miR-196a expression was significantly higher in the 10 cervical cancer tissue specimens compared with their normal tissue counterparts (Figure 1B), indicating that miR-196a is upregulated in cervical cancer.

miR-196a expression is correlated with clinical features and prognosis in cervical cancer patients. In order to determine whether there was any correlation between miR-196a expression and clinical features or prognosis of cervical cancer patients, we split the 92 patients into two groups based on miR-196a expression levels (low $v s$ high) with the median expression level as a cutoff point. The Kaplan-Meier analysis revealed that high miR-196a levels were significantly correlated with the reduced overall and disease-free survival in the 92 cervical cancer patients (Figure 2A and B). Upregulation of miR-196a was correlated with tumour stage $(P=0.011)$ but not with age, HPV status, tumour size, tumour differentiation or lymph node status (Supplementary Table 2).
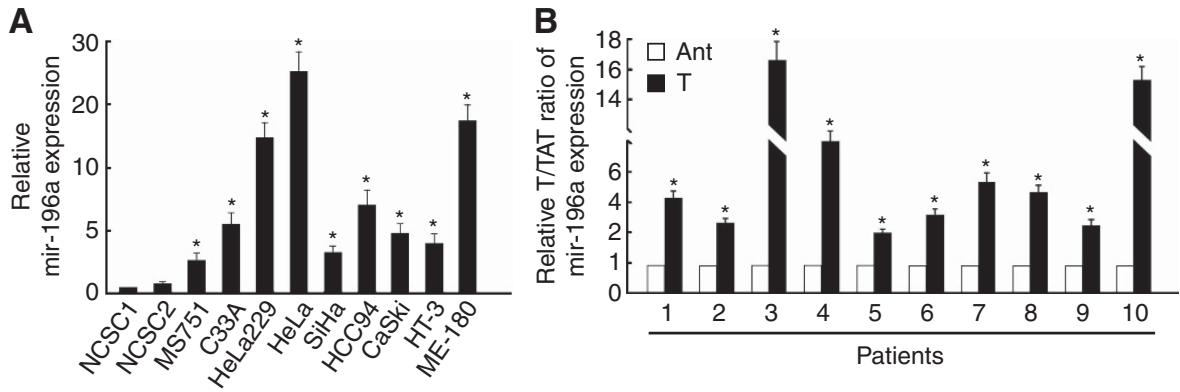

Figure 1. miR-196a expression is increased in cervical cancer tissues and cell lines. (A) Expression of miR-196a in normal cervical squamous cells (NCSCs) and cervical cancer cell lines (MS751, C33A, HeLa, HeLa229, SiHa, HCC94, CaSKi, HT-3 and ME-180) by real-time PCR. (B) Expression of miR-196a in 10 paired cervical tumour tissues (T) and their adjacent normal tissues (ANT) by real-time PCR. miR-196a expression was normalised by U6 expression. Scale bars represent the means of three independent experiments. ${ }^{\star} P<0.05$.
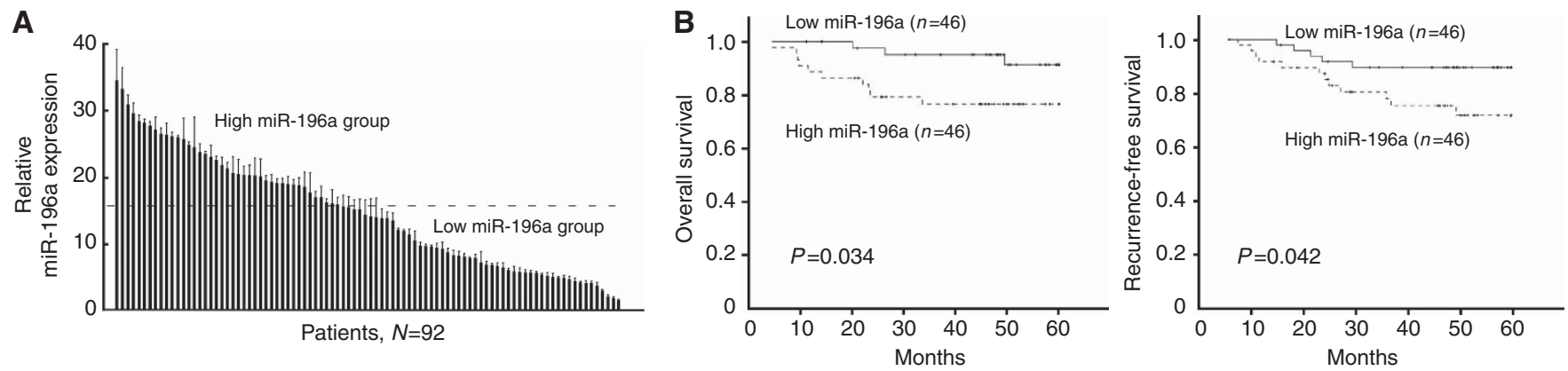

Figure 2. miR-196a expression correlates with poor survival in cervical cancer patients. (A) Expression levels of miR-196a in 92 cervical cancer samples by real-time PCR. miR-196a expression was normalised by U6 expression. (B) Kaplan-Meier curves revealed that patients with high levels of miR-196a expression showed reduced overall survival (left) and recurrence-free survival (right) rates compared with patients with low levels of miR-196a expression (log-rank test). Error bars represent mean \pm s.d. from three independent experiments. 
These results indicate an important role for miR-196a in cervical cancer progression and prognosis.

Overexpression of miR-196a enhances proliferation of cervical cancer cells. To analyse the effect of miR-196a on proliferation of cervical cancer cells, we transfected miR-196a mimics into C33A and CaSki cell lines. 3-(4,5-Dimethyl-2-thiazolyl)-2,5-diphenyl$2 \mathrm{H}$-tetrazoliumbromide and colony formation assays showed that overexpression of miR-196a dramatically increased the growth rate of both cervical cancer lines $v s$ the NC; (Figure 3A-C). In addition, a higher percentage of BrdU-positive cells were observed in miR196a-transfected C33A (57.2\%) and CaSki cells (55.1\%) compared with the NC cells (33 and 31\% for C33A and CaSki, respectively; (Figure 3D). Thus, upregulation of miR-196a promoted the proliferation of cervical cancer cells.

Inhibition of miR-196a reduces proliferation of cervical cancer cells. To further demonstrate the role of miR-196a on proliferation
A

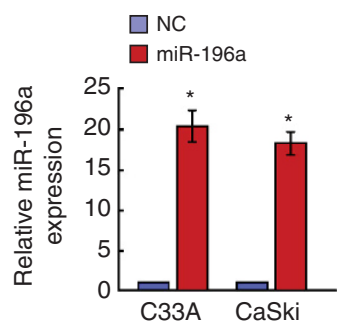

D

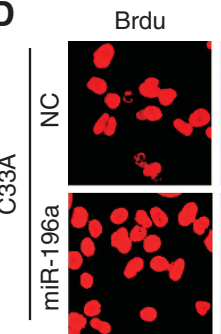

B
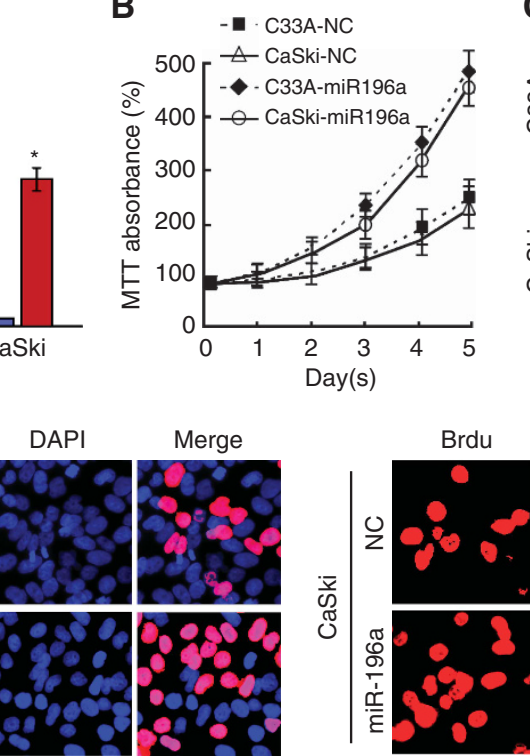

C

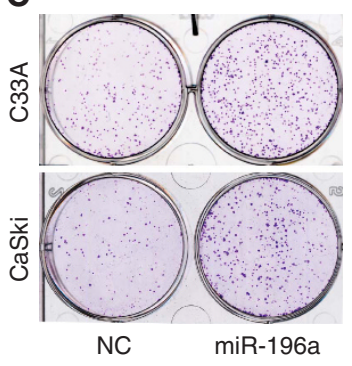

$\square \mathrm{NC}$

$\square$ miR-196a
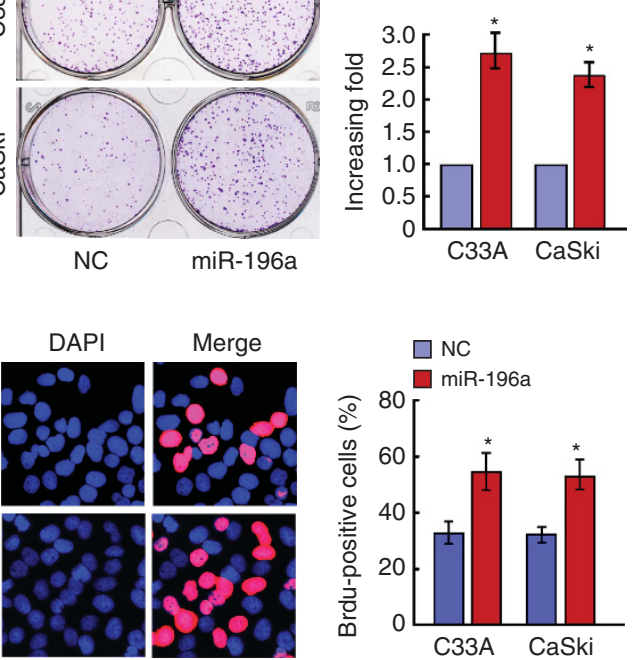

Figure 3. miR-196a upregulation promotes proliferation of cervical cancer cells. (A) Expression of miR-196a in C33A and CaSki cells transfected with miR-196a mimics (miR-196a) by real-time PCR. (B) Effects of miR-196a overexpression on the growth of cervical cancer cells C33A and CaSKi. 3-(4,5-Dimethyl-2-thiazolyl)-2,5-diphenyl-2H-tetrazoliumbromide assays showed that miR-196a-transfected C33A and CaSKi cells proliferated more rapidly than the control cells. (C) Representative micrographs (left) and quantification (right) of crystal violet-stained cell colonies. (D) Representative micrographs (left) and quantification (right) of BrdU-incorporating cells after transfection with miR-196a or negative control (NC). Error bars represent mean \pm s.d. from three independent experiments. ${ }^{\star} P<0.05$.
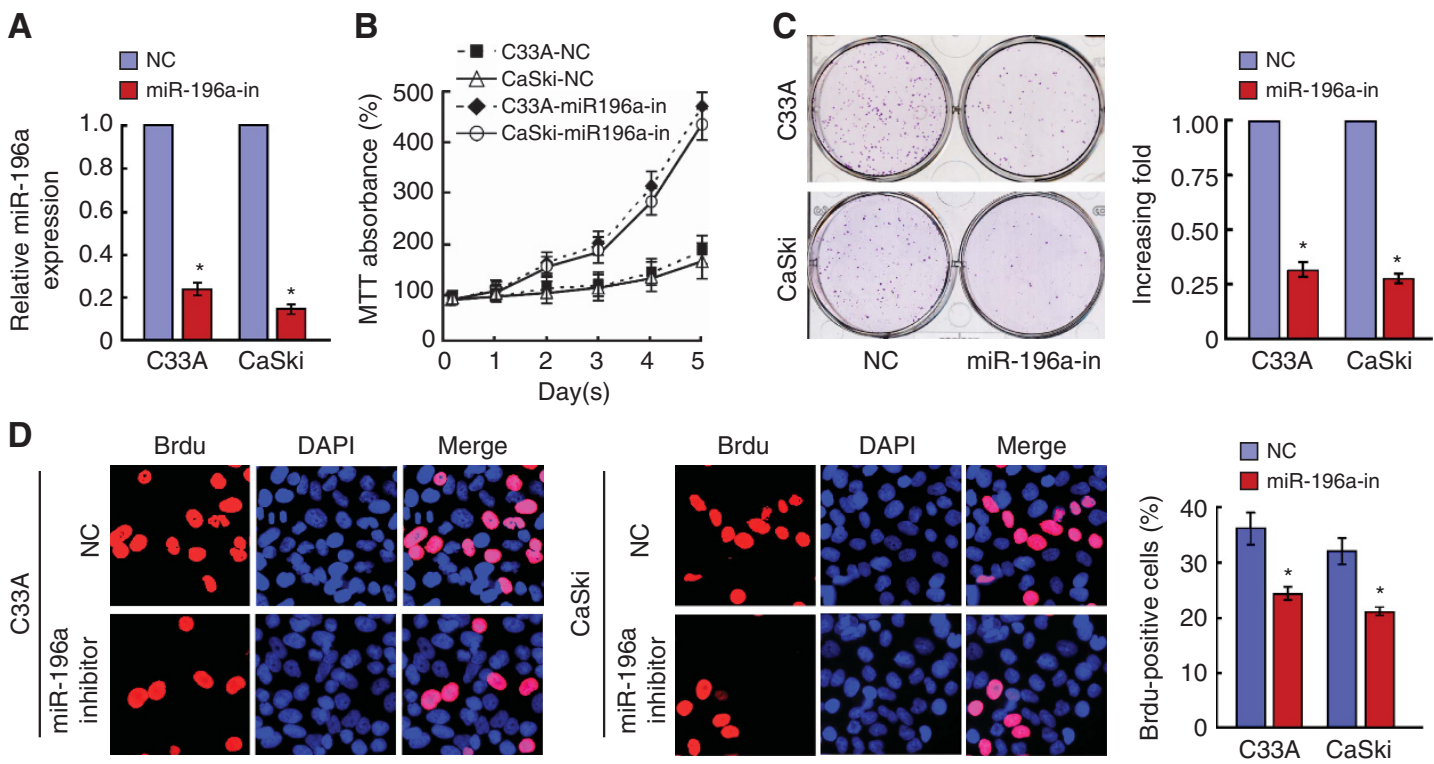

Figure 4. miR-196a inhibition reduces proliferation of cervical cancer cells. (A) Expression of miR-196a in C33A and CaSki cells transfected with miR-196a inhibitor (miR-196a-in) by real-time PCR. (B) Effects of miR-196a inhibition on the growth of cervical cancer cells C33A and CaSKi. 3-(4,5-Dimethyl-2-thiazolyl)-2,5-diphenyl-2H-tetrazoliumbromide assays showed that inhibition of miR-196a reduced cell proliferation. (C) Representative micrographs (left) and quantification (right) of crystal violet-stained cell colonies. (D) Representative micrographs (left) and quantification (right) of BrdU-incorporating cells after transfection with miR-196a inhibitor or negative control (NC). Error bars represent mean \pm s.d. from three independent experiments. ${ }^{\star} P<0.05$. 
of cervical cancer cells, we transfected an miR-196a inhibitor into $\mathrm{C} 33 \mathrm{~A}$ and CaSki cell lines. As shown in Figure 4A-C, overexpression of the miR-196a inhibitor significantly decreased the growth rate of both cervical cancer lines as compared with the NC. Moreover, a lower percentage of BrdU-positive cells were observed in miR-196a inhibitor-transfected C33A (23.8\%) and CaSki cells (22.1\%) than in the NC cells $(37.2$ and $33.0 \%$ for C33A and CaSki, respectively; Figure 4D). Thus, downregulation of miR-196a suppressed the proliferation of cervical cancer cells.

Effect of miR-196a on cell cycle in vitro. As miR-196a significantly affected cell proliferation in C33A and CaSki cells, we hypothesised that miR-196a could function by affecting the cell cycle of cervical cancer cells. We tested this hypothesis by flow cytometry. The results revealed that ectopic expression of miR196a drastically decreased the percentage of cells in the G1/G0 peak and increased the percentage of cells in the $\mathrm{S}$ peak in both C33A and CaSki cells compared with NC cells (Figure 5A and C). Overexpressing the miR-196a inhibitor dramatically increased the number of cells in the G0/G1 peak and decreased those in the $S$ peak (Figure 5B and C). Thus, overexpression of miR-196a may enhance the proliferation of cervical cancer cells by promoting the G1/S cell cycle transition.

miR-196a decreases cell cycle inhibitor $\mathrm{p}^{2} 1^{\mathrm{Cip} 1}$ and increases cell cycle regulator cyclin D1. As overexpression of miR-196a appears tightly linked to the proliferation of cervical cancer cells, we further investigated whether the CDK inhibitor $\mathrm{p} 21^{\mathrm{Cip} 1}$ or the CDK regulator cyclin D1 could be regulated by miR-196a. Western blotting and real-time PCR analysis revealed that $\mathrm{p} 21^{\mathrm{Cip} 1}$ was downregulated, whereas cyclinD1 was upregulated in miR196a-transfected cells compared with NC-transfected cells (Figure 5A and B). These results supported our hypothesis that miR-196a has a critical role in the growth of cervical cancer cells.

FOXO1 and $\mathrm{p}^{2} 7^{\mathrm{Kip} 1}$ are direct targets of miR-196a in cervical cancer cells. To identify the target genes of miR-196a regulation, we searched publicly available databases (TargetScan, Pictar, miRANDA) and selected FOXO1 and $\mathrm{p} 27^{\mathrm{Kip} 1}$ as potential downstream target genes (Figure 6C). As predicted, western blotting revealed that ectopic expression of miR-196a in C33A and CaSki cells decreased the expression of FOXO1 and p27 $7^{\mathrm{Kip} 1}$ proteins, whereas ectopic expression of the miR-196a inhibitor increased their expression (Figure 6D). Moreover, ectopic expression of miR-196a decreased FOXO1 transcriptional activity, whereas inhibition of miR-196a increased transcriptional activity of FOXO1 in both cell lines (Figure 6E). We then subcloned the $3^{\prime}$-UTRs of FOXO1 and p $27^{\text {Kip1 }}$ into the pGL3 luciferase reporter. As shown in Figure 6F, transfection of miR-196a consistently suppressed the luciferase activity of the FOXO1 and p27 3'-UTR luciferase reporter plasmids in both $\mathrm{C} 33 \mathrm{~A}$ and CaSki cells, whereas transfection of the miR-196a inhibitor rescued the suppression. Point mutations in the miR-196a-binding seed region of the
A
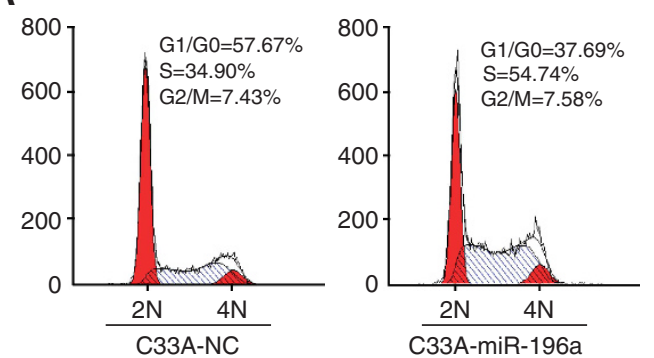

B

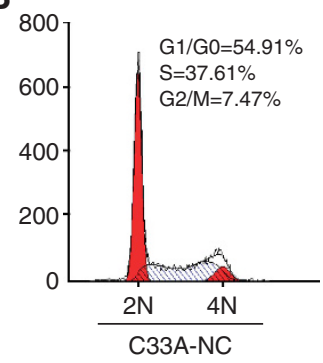

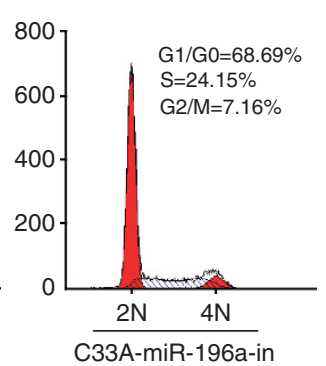
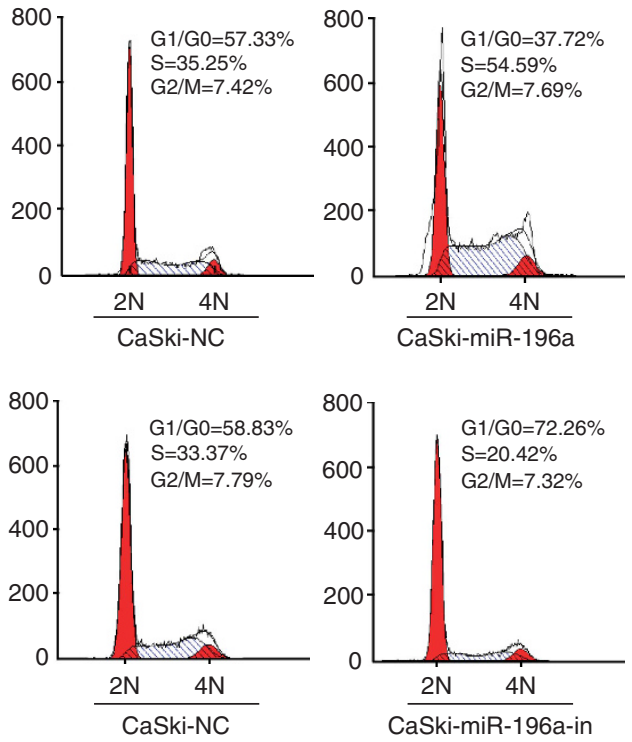

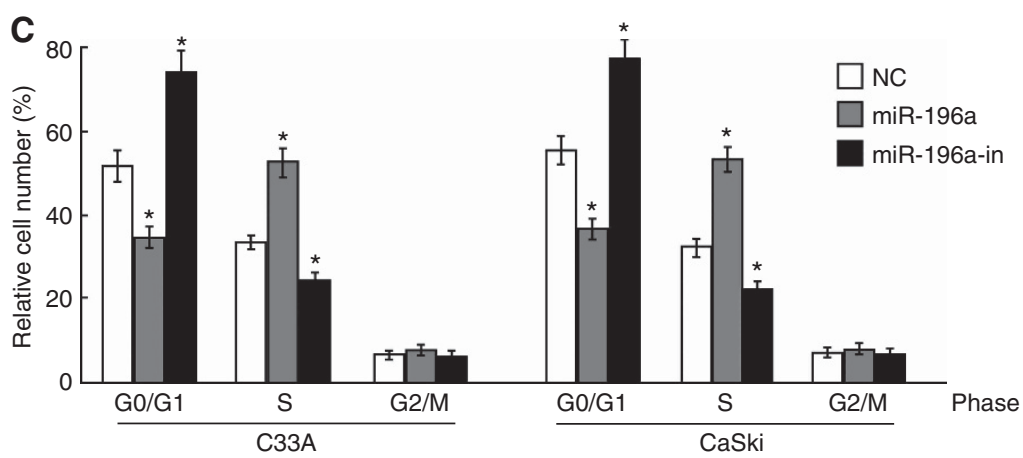

Figure 5. miR-196a induces proliferation by promoting the G1/S transition. (A) Flow cytometric analysis of C33A and CaSKi cells transfected with miR-196a mimic or negative control (NC) $48 \mathrm{~h}$ after transfection. (B) Flow cytometric analysis of C33A and CaSKi cells transfected with miR-196a inhibitor or NC $48 \mathrm{~h}$ after transfection. (C) Statistical analysis of the change in cell proportion at each phase of the cell cycle after treatment with miR-196a or miR-196a inhibitor. Error bars represent mean \pm s.d. from three independent experiments. ${ }^{\star} P<0.05$. 
A

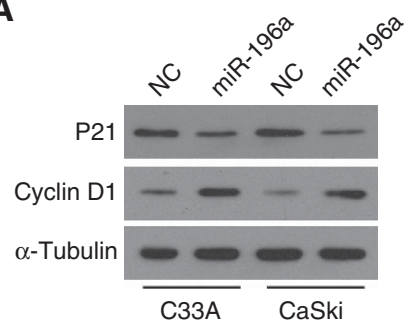

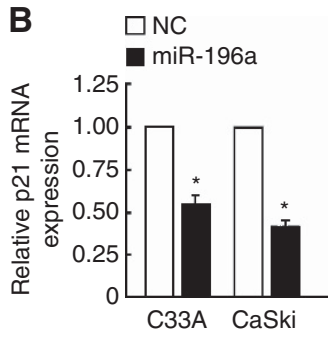

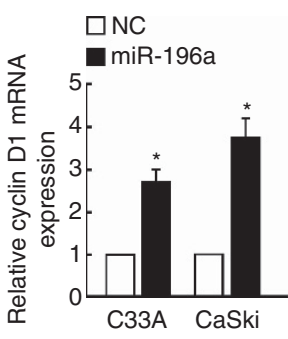

C

FOXO1-3'UTR 5' 455 UAAACUUUUGUUUGUACUACCUG 477 3' miR-196a 3' GGGUUGUUGUACUUÚGAUGGAU 5' FOXO1-3'UTR-mut 5' 455 UAAACUUUUGUUUGUACUÁGGAG 477 3' p27-3'UTR 5' 230 UaUUUgCUUCAUUgUaCUACCUg 252 3' miR-196a 3' GgGUUGUUGUACUUUGAUGGAU 5' p27-3'UTR-mut 5' 230 UAUUUGCUUCAUUGUACUAGGAG 252 3'

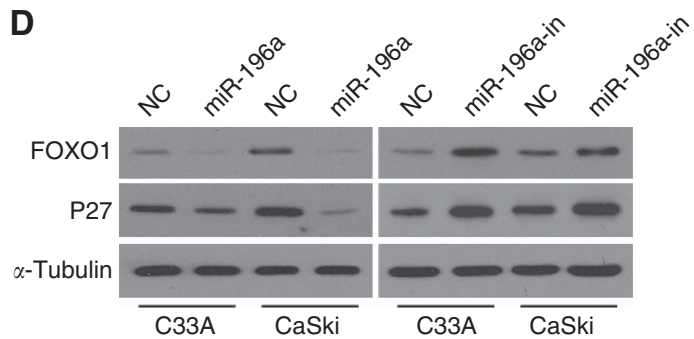

$\mathbf{E}$

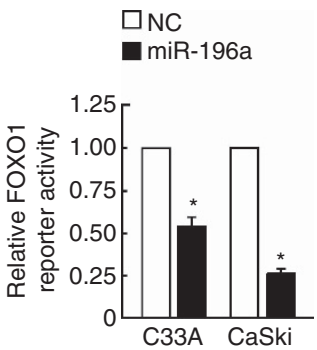

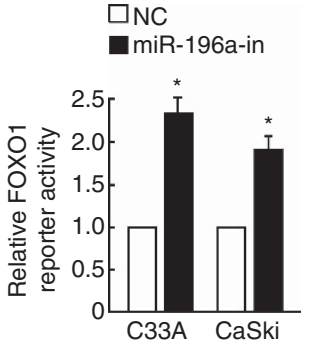

$\mathbf{F}$

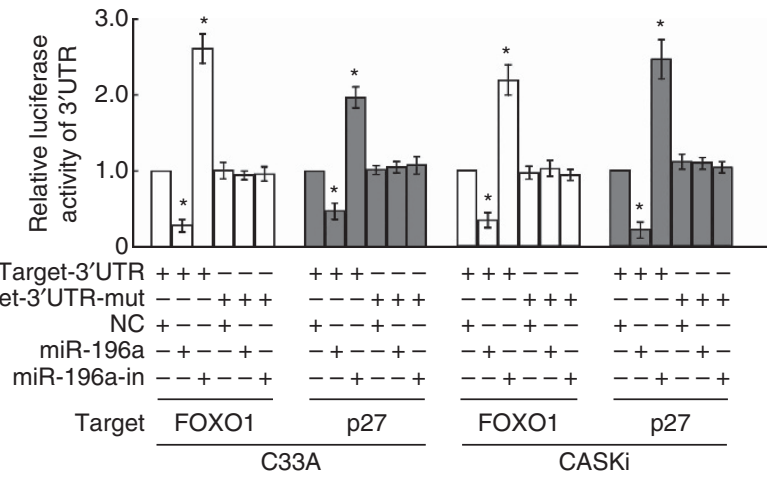

Figure 6. FOXO1 and $\mathrm{p} 27^{\mathrm{Kip} 1}$ are direct targets of miR-196a. (A) Expression of p21 Cip1 and cyclin D1 in C33A and CaSKi cells after transfection with miR-196a or NC by western blot analysis. $\alpha$-Tubulin was used as a loading control. (B) Expression of p2 $1^{\text {Cip } 1}$ and cyclin D1 in indicated cells by real-time PCR. (C) Predicted miR-196a target sequences in the $3^{\prime}$-UTRs of FOXO1 and p21 Cip1 genes. (D) Expression of p27Kip1 and FOXO1 in indicated cells by western blot analysis. $\alpha$-Tubulin was used as a loading control. (E) Relative FOXO1 reporter activities in the indicated cell lines. (F) Luciferase assays on C33A and CaSKi cells transfected with the pGL3 control reporter, pGL3-target-3'-UTR reporter, or pGL3- target -3'-UTR-mut reporter and increasing amounts of miR-196a mimic or miR-196a inhibitor oligonucleotides, as indicated. Error bars represent mean \pm s.d. from three independent experiments. ${ }^{\star} P<0.05$.

FOXO1 or p27 $3^{\prime}$-UTR abrogated the repressive effect of miR-196a. Thus, the data suggest that FOXO1and $\mathrm{p} 27^{\text {Kip } 1}$ are genuine targets of miR-196a.

FOXO1 is involved in miR-196a-induced cell proliferation of cervical cancer. To further elucidate the function of miR196a-induced proliferation through FOXO1 repression, FOXO1 (without $3^{\prime}$-UTR) and FOXO1-3'-UTR (with $3^{\prime}$-UTR) were transfected into miR-196a-overexpressing cells. As expected, western blotting revealed that FOXO1 was significantly downregulated upon miR-196a transfection but was rescued after transfection of FOXO1$3^{\prime}$-UTR (Figure 7A). Overexpressing miR-196a significantly changed the expression of $\mathrm{p} 21^{\mathrm{Cip} 1}$ and cyclin D1. The effects of miR-196a on the modulation of $\mathrm{p} 21^{\mathrm{Cip} 1}$ and cyclin $\mathrm{D} 1$ could be reversed by ectopic expression of FOXO1 but were unaffected by transfection of FOXO1-3'-UTR (Figure 7B). We also observed that the luciferase activity of the FOXO1 reporter was decreased in miR-196a-overexpressing cells. The inhibitory effects of miR-196a could be abolished upon transfection with FOXO1 but not with FOXO1-3'-UTR (Figure 7C). Moreover, MTT assay showed that co-transfection of miR-196a and FOXO1 could rescue the miR-196a-promoted proliferation, whereas co-transfection of miR-196a and FOXO1-3'-UTR could not (Figure 7D). Furthermore, miR-196a and cyclin D1 mRNA expression were dramatically upregulated, whereas the expression level of p21 ${ }^{\text {Cip1 }}$ mRNA was downregulated in cervical carcinoma tissues as compared with normal cervical tissues (Figure 7E). To examine the relationship between miR-196a and FOXO1 expression in cervical cancer, the expression level of FOXO1 protein in eight freshly prepared cervical cancer tissue samples was examined. Statistical analysis demonstrated that miR-196a expression was inversely correlated with FOXO1 expression $(r=-0.784, P=0.007$; Figure 7F). Collectively, these results suggest that miR-196a promotes cellular proliferation by inhibition of FOXO1.

\section{DISCUSSION}

This study showed that miR-196a expression was significantly upregulated in human cervical cancer tissues and cell lines and that this upregulation was associated with tumour stage and prognosis. In addition, ectopic expression of miR-196a promoted G1/S-phase transition and cell proliferation in cervical cancer cell lines, whereas silencing of miR-196a reduced these effects. Additional in vitro studies showed that FOXO1 and $\mathrm{p} 27^{\mathrm{Kip} 1}$ are direct targets of miR-196a. Our study suggests that miR-196a may have an essential role in the tumorigenesis and progression of cervical cancer. 

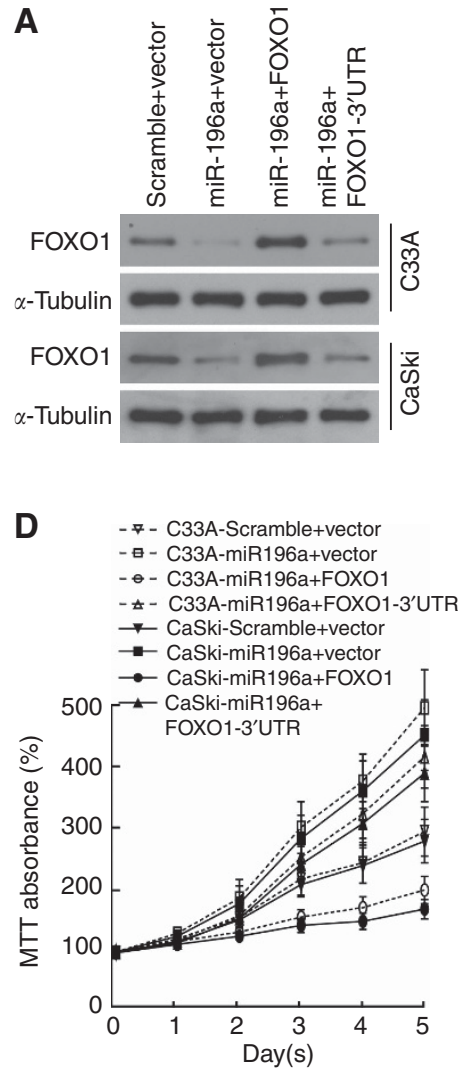

B
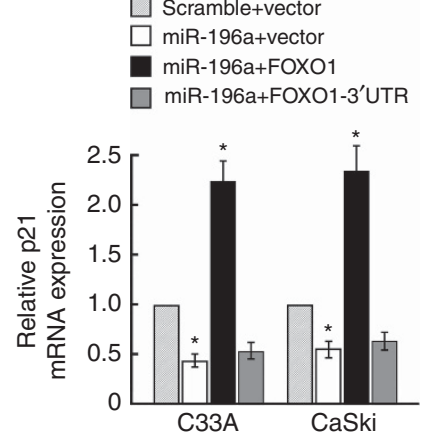

E

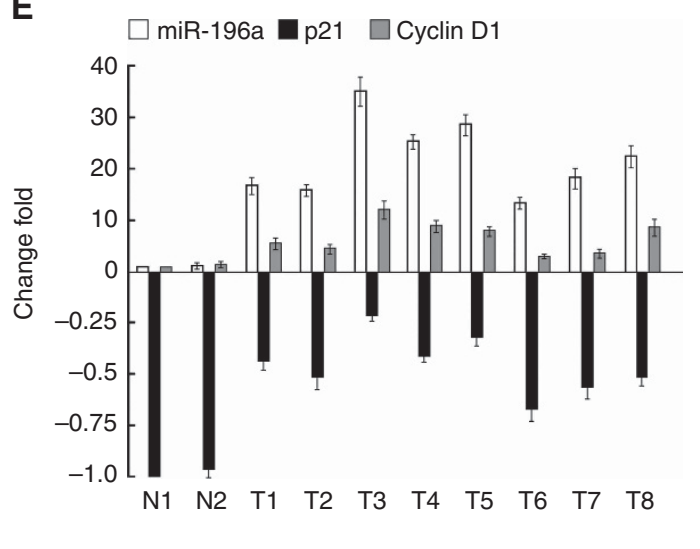

C

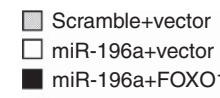

miR-196a+FOXO1

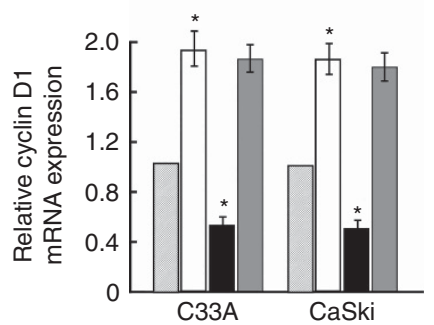

$\square$ miR-196a+FOXO1-3'UTR

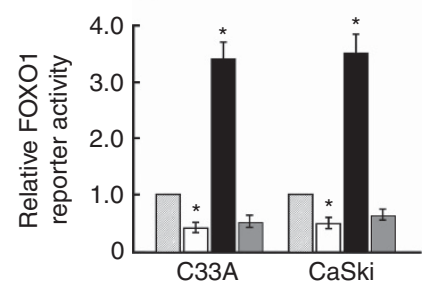

$\mathbf{F}$
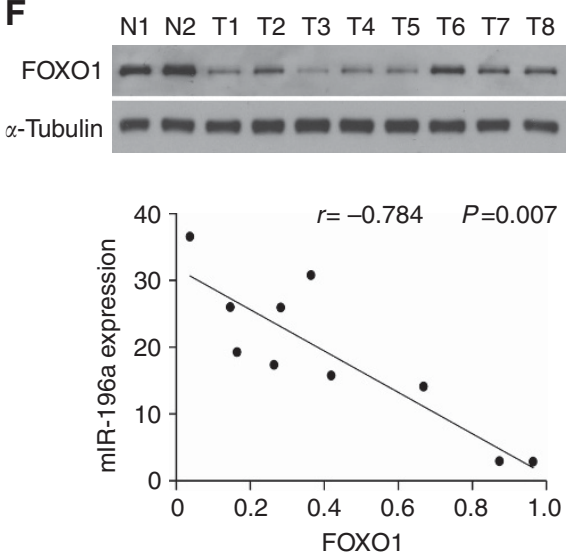

Figure 7. FOXO1 mediates miR-196a-induced cervical cancer cell proliferation. (A) FOXO1 protein expression in the indicated cell lines by western blot analysis. (B) Expression of $\mathrm{p} 21^{\mathrm{Cip} 1}$ and cyclin D1 mRNA in C33A and CaSKi cells by real-time PCR. GAPDH was used as a loading control. (C) Relative FOXO1 reporter activities in the indicated cell lines. (D) 3-(4,5-Dimethyl-2-thiazolyl)-2,5-diphenyl-2H-tetrazoliumbromide assay of cervical cancer cells transfected with either scramble, miR-196a mimic, miR-196a and FOXO1 (without 3'-UTR), or with miR-196a and FOXO1-3'UTR (with 3'-UTR). (E) Expression of miR-196a, p21 Cip1 and cyclin D1 by real-time PCR in two freshly prepared normal human cervical tissues and eight human cervical carcinoma tissues. (F) The expression and correlation of miR-196a and FOXO1 in normal human cervical vs cervical carcinoma tissues as in $\mathbf{E}$. Error bars represent mean \pm s.d. from three independent experiments. ${ }^{\star} P<0.05$.

The PI3K/Akt signalling pathway is involved in tumour cell proliferation during the development of cervical cancer, and downstream effectors of PI3K/Akt signalling are promising targets for cervical cancer therapy (Wu et al, 2013). In the present study, we identified miR-196a as a candidate oncogenic miR by targeting PI3K/Akt in cervical carcinogenesis. miR-196a is located in the vertebrate homoeobox $(H O X)$ gene cluster region, which encodes homoeodomain-containing transcription factors that regulate differential genetic programmes during embryonic development (Alonso, 2002; Woltering and Durston, 2008). The expression of miR-196a is influenced by regulatory controls imposed on the HOX clusters (Mansfield et al, 2004). Previous studies have demonstrated that miR-196a expression is upregulated in several cancers, including oesophageal adenocarcinoma, pancreatic cancer, breast cancer, leukaemia and colorectal cancer (Hui et al, 2009; Maru et al, 2009; Schimanski et al, 2009; Schotte et al, 2009; Zhang et al, 2009). However, there have been no reports on miR-196a oncogenic function in cervical cancer. In the present study, we found that miR-196a was markedly upregulated in cervical cancer cell lines compared with normal cervical cells and that overexpression of miR-196a in cervical cancer cell lines promoted tumour cell proliferation. Interestingly, highly proliferative cells, such as HeLa, HeLa229 and ME-180 (Vannucchi et al, 2000; Kwan et al, 2013), express high levels of miR-196a. Moreover, miR-196a expression was dramatically upregulated in cervical cancer specimens compared with adjacent normal cervix, and higher miR-196a expression was significantly correlated with advanced tumour stage and poor clinical prognosis in cervical cancer patients.
These studies implicate miR-196a as an oncogenic miR and indicate that miR-196a may have an important role in cervical cancer development.

By using several algorithms, we identified FOXO1 and p2 $7^{\text {Kip1 }}$ as potential targets of miR-196a. The luciferase activity assay and point mutation analysis demonstrated that the downregulation of FOXO1 and $27^{\mathrm{Kip} 1}$ was mediated by miR196-a through the FOXO1-3'-UTR and the p27-3'-UTR, respectively. Transfection of C33A and CaSki cells with FOXO1 (without $3^{\prime}$-UTR) significantly inhibited miR-196a-induced proliferation, whereas transfection with FOXO1-3'-UTR (with $3^{\prime}$-UTR) only partially suppressed the proliferation induced by miR-196a overexpression. Expression of FOXO1 and p2 $7^{\text {Kipl }}$ proteins was also significantly downregulated in miR-196a-overexpressing C33A and CaSki cells. Moreover, we observed an inverse correlation of miR-196a and FOXO1 protein expression in cervical cancer cell lines and clinical samples. Thus, we concluded that miR-196a mediates cervical cancer cell proliferation by targeting the $3^{\prime}$-UTRs of FOXO1 and $\mathrm{p} 27^{\mathrm{Kip} 1}$.

The Forkhead box O (FOXO) proteins (FOXO1, FOXO3a, FOXO4 and FOXO6) are key effectors of PI3K/Akt signalling and regulate many biological processes, such as cell cycle regulation, cell differentiation, tumorigenesis and oxidative stress responses (Huang and Tindall, 2007; Kousteni, 2011). FOXO expression leads to G1/S arrest, resulting from increased expression of cyclindependent kinase inhibitors $\mathrm{p} 21^{\mathrm{Cip} 1}$ and $\mathrm{p} 27^{\mathrm{Kip} 1}$, and downregulation of cyclin D1 (Schmidt et al, 2002; Huang and Tindall, 2007; Zhang et al, 2011). Of the FOXO family members, only FOXO1 has been shown to have a crucial role in female genital 
tract cancer development. Myatt et al (2010) revealed that repression of FOXO1 resulted in a deregulated cell cycle and impaired cell death control, which might have a central role in endometrial tumorigenesis. Magro et al (2012) discovered that the FOXO1 gene was monoallelically deleted in most cases of vaginal myofibroblastoma. Our study is the first to have identified FOXO1 as a genuine target of miR-196a, suggesting a crucial functional role of FOXO1 in cervical tumorigenesis. In line with our study, Tang et al (2013) found that overexpression of miR-182 was associated with a decreased expression of FOXO1 in HeLa cells. Similarly, Wu et al (2012) showed that miR-233 expression was inversely correlated with FOXO1 expression and cell cycle arrest in HeLa cells. However, neither study identified FOXO1 as a direct target of the two miRNAs.

We also identified p $27^{\text {Kip } 1}$, a downstream effector of FOXO1, as a target of miR-196a. As a tight modulator of CDK-dependent phenotypes, p27 ${ }^{\text {Kip1 }}$ correlates with tumour growth and aggressiveness. When $\mathrm{p} 27^{\mathrm{Kip} 1}$ is localised in the cytosol, it acts as a cytoskeleton-remodelling protein. In the nucleus, $\mathrm{p} 27^{\mathrm{Kip} 1}$ functions as an anti-proliferative protein (Borriello et al, 2011). In the cancer research field, it is known that ectopic expression of $\mathrm{p} 27^{\text {Kip } 1}$ induces growth arrest of cancer cells and suppresses cancer xenograft growth (Park et al, 2001). Transactivation of $\mathrm{p} 27^{\mathrm{Kip} 1}$ inhibits cancer cell growth (Wu and Zheng, 2013). It has also been reported that miR-196a could promote gastric cancer cell proliferation by downregulating $\mathrm{p} 27^{\mathrm{Kip} 1}$ (Sun et al, 2012). Our results are similar to this report, implying that $\mathrm{p} 27^{\mathrm{Kip} 1}$ could be downregulated by $\mathrm{miR}$ in cervical cancer. Further studies are required to examine whether other miRNAs or mechanisms can regulate FOXO1/p2 $27^{\mathrm{Kip} 1}$ expression in cervical cancer, and whether miR-196a can target other isoforms of the FOXO family or cell cycle regulators.

In summary, the present study identified for the first time the correlation between miR-196a-mediated cervical cancer cell proliferation and downregulation of FOXO1 and $\mathrm{p} 27^{\mathrm{Kip} 1}$. Our findings revealed a crucial role for miR-196a in regulating cell cycle checkpoints and cervical cancer cell proliferation. Understanding the precise role had by miR-196a in inducing tumour cell proliferation will increase our understanding of the biology of cervical cancer and inhibition of miR-196a may represent a novel therapeutic strategy in the treatment of cervical cancer.

\section{CONFLICT OF INTEREST}

The authors declare no conflict of interest.

\section{REFERENCES}

Alonso CR (2002) Hox proteins: sculpting body parts by activating localized cell death. Curr Biol 12: R776-R778.

Ambros V (2004) The functions of animal microRNAs. Nature 431: 350-355. Borriello A, Bencivenga D, Criscuolo M, Caldarelli I, Cucciolla V, Tramontano A, Borgia A, Spina A, Oliva A, Naviglio S, Della Ragione F (2011) Targeting p27Kip1 protein: its relevance in the therapy of human cancer. Expert Opin Ther Targets 15: 677-693.

Castellsague X (2008) Natural history and epidemiology of HPV infection and cervical cancer. Gynecol Oncol 110: S4-S7.

Castellsague X, Diaz M, de Sanjose S, Munoz N, Herrero R, Franceschi S, Peeling RW, Ashley R, Smith JS, Snijders PJ, Meijer CJ, Bosch FX (2006) Worldwide human papillomavirus etiology of cervical adenocarcinoma and its cofactors: implications for screening and prevention. J Natl Cancer Inst 98: 303-315.

Chakrabarti O, Veeraraghavalu K, Tergaonkar V, Liu Y, Androphy EJ, Stanley MA, Krishna S (2004) Human papillomavirus type 16 E6 amino acid 83 variants enhance E6-mediated MAPK signaling and differentially regulate tumorigenesis by notch signaling and oncogenic Ras. J Virol 78: 5934-5945.
Du CX, Wang Y (2012) Expression of P-Akt, NFkappaB and their correlation with human papillomavirus infection in cervical carcinoma. Eur J Gynaecol Oncol 33: 274-277.

Haie-Meder C, Morice P, Castiglione M (2010) Cervical cancer: ESMO Clinical Practice Guidelines for diagnosis, treatment and follow-up. Ann Oncol 21(Suppl 5): v37-v40.

Huang H, Regan KM, Wang F, Wang D, Smith DI, van Deursen JM, Tindall DJ (2005) Skp2 inhibits FOXO1 in tumor suppression through ubiquitin-mediated degradation. Proc Natl Acad Sci USA 102: 1649-1654

Huang H, Tindall DJ (2007) Dynamic FoxO transcription factors. J Cell Sci 120: 2479-2487.

Hui AB, Shi W, Boutros PC, Miller N, Pintilie M, Fyles T, McCready D, Wong D, Gerster K, Waldron L, Jurisica I, Penn LZ, Liu FF (2009) Robust global micro-RNA profiling with formalin-fixed paraffin-embedded breast cancer tissues. Lab Invest 89: 597-606.

Jemal A, Bray F, Center MM, Ferlay J, Ward E, Forman D (2011) Global cancer statistics. CA Cancer J Clin 61: 69-90.

Kloosterman WP, Plasterk RH (2006) The diverse functions of microRNAs in animal development and disease. Dev Cell 11: 441-450.

Kousteni S (2011) FoxO1: a molecule for all seasons. J Bone Miner Res 26: 912-917.

Kwan HT, Chan DW, Cai PC, Mak CS, Yung MM, Leung TH, Wong OG, Cheung AN, Ngan HY (2013) AMPK activators suppress cervical cancer cell growth through inhibition of DVL3 mediated Wnt/beta-catenin signaling activity. PLoS One 8: e53597.

Li J, Zhang N, Song LB, Liao WT, Jiang LL, Gong LY, Wu J, Yuan J, Zhang HZ, Zeng MS, Li M (2008) Astrocyte elevated gene-1 is a novel prognostic marker for breast cancer progression and overall patient survival. Clin Cancer Res 14: 3319-3326.

Lin H, Dai T, Xiong H, Zhao X, Chen X, Yu C, Li J, Wang X, Song L (2010) Unregulated miR-96 induces cell proliferation in human breast cancer by downregulating transcriptional factor FOXO3a. PLoS One 5: e15797.

Magro G, Righi A, Casorzo L, Antonietta T, Salvatorelli L, Kacerovska D, Kazakov D, Michal M (2012) Mammary and vaginal myofibroblastomas are genetically related lesions: fluorescence in situ hybridization analysis shows deletion of 13q14 region. Hum Pathol 43: 1887-1893.

Mansfield JH, Harfe BD, Nissen R, Obenauer J, Srineel J, Chaudhuri A, Farzan-Kashani R, Zuker M, Pasquinelli AE, Ruvkun G, Sharp PA, Tabin CJ, McManus MT (2004) MicroRNA-responsive 'sensor' transgenes uncover Hox-like and other developmentally regulated patterns of vertebrate microRNA expression. Nat Genet 36: 1079-1083.

Maru DM, Singh RR, Hannah C, Albarracin CT, Li YX, Abraham R, Romans AM, Yao H, Luthra MG, Anandasabapathy S, Swisher SG, Hofstetter WL, Rashid A, Luthra R (2009) MicroRNA-196a is a potential marker of progression during Barrett's metaplasia-dysplasia-invasive adenocarcinoma sequence in esophagus. Am J Pathol 174: 1940-1948.

Menges CW, Baglia LA, Lapoint R, McCance DJ (2006) Human papillomavirus type $16 \mathrm{E} 7$ up-regulates AKT activity through the retinoblastoma protein. Cancer Res 66: 5555-5559.

Myatt SS, Wang J, Monteiro LJ, Christian M, Ho KK, Fusi L, Dina RE, Brosens JJ, Ghaem-Maghami S, Lam EW (2010) Definition of microRNAs that repress expression of the tumor suppressor gene FOXO1 in endometrial cancer. Cancer Res 70: 367-377.

Park KH, Seol JY, Yoo CG, Kim YW, Han SK, Lee EH, Kim CM, Shim YS, Lee CT (2001) Adenovirus expressing p27(Kip1) induces growth arrest of lung cancer cell lines and suppresses the growth of established lung cancer xenografts. Lung Cancer 31: 149-155.

Pecorelli S (2009) Revised FIGO staging for carcinoma of the vulva, cervix, and endometrium. Int J Gynaecol Obstet 105: 103-104.

Schimanski CC, Frerichs K, Rahman F, Berger M, Lang H, Galle PR, Moehler M, Gockel I (2009) High miR-196a levels promote the oncogenic phenotype of colorectal cancer cells. World J Gastroenterol 15: 2089-2096.

Schmidt M, Fernandez de Mattos S, van der Horst A, Klompmaker R, Kops GJ, Lam EW, Burgering BM, Medema RH (2002) Cell cycle inhibition by FoxO forkhead transcription factors involves downregulation of cyclin D. Mol Cell Biol 22: 7842-7852.

Schotte D, Chau JC, Sylvester G, Liu G, Chen C, van der Velden VH, Broekhuis MJ, Peters TC, Pieters R, den Boer ML (2009) Identification of new microRNA genes and aberrant microRNA profiles in childhood acute lymphoblastic leukemia. Leukemia 23: 313-322. 
Schwarz JK, Payton JE, Rashmi R, Xiang T, Jia Y, Huettner P, Rogers BE, Yang Q, Watson M, Rader JS, Grigsby PW (2012) Pathway-specific analysis of gene expression data identifies the PI3K/Akt pathway as a novel therapeutic target in cervical cancer. Clin Cancer Res 18: 1464-1471.

Sun M, Liu XH, Li JH, Yang JS, Zhang EB, Yin DD, Liu ZL, Zhou J, Ding Y, Li SQ, Wang ZX, Cao XF, De W (2012) MiR-196a is upregulated in gastric cancer and promotes cell proliferation by downregulating p27(kip1). Mol Cancer Ther 11: 842-852.

Tang T, Wong HK, Gu W, Yu MY, To KF, Wang CC, Wong YF, Cheung TH, Chung TK, Choy KW (2013) MicroRNA-182 plays an onco-miRNA role in cervical cancer. Gynecol Oncol 129(1): 199-208.

Vannucchi S, Percario ZA, Chiantore MV, Matarrese P, Chelbi-Alix MK, Fagioli M, Pelicci PG, Malorni W, Fiorucci G, Romeo G, Affabris E (2000) Interferon-beta induces $\mathrm{S}$ phase slowing via up-regulated expression of PML in squamous carcinoma cells. Oncogene 19: 5041-5053.

Woltering JM, Durston AJ (2008) MiR-10 represses HoxB1a and HoxB3a in zebrafish. PLoS One 3: e1396.

Wu J, Chen C, Zhao KN (2013) Phosphatidylinositol 3-kinase signaling as a therapeutic target for cervical cancer. Curr Cancer Drug Targets 13: 143-156.

Wu L, Li H, Jia CY, Cheng W, Yu M, Peng M, Zhu Y, Zhao Q, Dong YW, Shao K, Wu A, Wu XZ (2012) MicroRNA-223 regulates FOXO1 expression and cell proliferation. FEBS Lett 586: 1038-1043.
Wu X, Liu T, Fang O, Leach LJ, Hu X, Luo Z (2013) miR-194 suppresses metastasis of non-small cell lung cancer through regulating expression of BMP1 and p27 $7^{\mathrm{kip} 1}$. Oncogene; e-pub ahead of print 15 April 2013; doi:10.1038/onc.2013.108.

Wu XL, Zheng PS (2013) Undifferentiated embryonic cell transcription factor-1 (UTF1) inhibits the growth of cervical cancer cells by transactivating p27Kip1. Carcinogenesis 34(7): 1660-1668.

Zhang H, Pan Y, Zheng L, Choe C, Lindgren B, Jensen ED, Westendorf JJ, Cheng L, Huang H (2011) FOXO1 inhibits Runx2 transcriptional activity and prostate cancer cell migration and invasion. Cancer Res 71: 3257-3267.

Zhang Y, Gan B, Liu D, Paik JH (2011) FoxO family members in cancer. Cancer Biol Ther 12: 253-259.

Zhang Y, Li M, Wang H, Fisher WE, Lin PH, Yao Q, Chen C (2009) Profiling of 95 microRNAs in pancreatic cancer cell lines and surgical specimens by real-time PCR analysis. World J Surg 33: 698-709.

This work is published under the standard license to publish agreement. After 12 months the work will become freely available and the license terms will switch to a Creative Commons AttributionNonCommercial-Share Alike 3.0 Unported License.

Supplementary Information accompanies this paper on British Journal of Cancer website (http://www.nature.com/bjc) 